Revista ta Rede Amazonitica de Eduraçäo

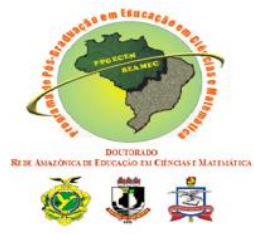

\title{
A LUDICIDADE NO ENSINO DA GEOMETRIA NO 5 ANO DO ENSINO FUNDAMENTAL
}

Lúcia Helena Soares de Oliveira ${ }^{a}$ Débora Regina Soares de Oliveira ${ }^{b}$ Eraldo Gonçalves Rocha Cézar Junior ${ }^{\mathbf{c}}$ Fabielly Santos Rodrigues ${ }^{\mathbf{d}}$

\section{A R T I C L E I N F O}

Palavras chave:

Práxis.

Formação de Professor.

Ensino de Ciências.

E-mail:

a oliveiralucia63@hotmail.com

b deborarsdo@gmail.com

c eraldogoncalvesj@gmail.com

d fabielly_santos@ hotmail.com

\section{R E S U M O}

O presente trabalho é resultado de pesquisa objetivando investigar qual método seria mais eficiente para a aprendizagem dos conceitos de espaço e forma no Ensino Fundamental. Para o desenvolvimento da investigação e visando a articulação teórico-metodológica optou-se por trabalhar a pesquisa numa abordagem de métodos mistos em que houve uma triangulação concomitante dos dados. Os participantes foram 215 alunos e 06 professores do $5^{\circ}$ ano de uma Escola Municipal localizada na cidade de Manaus no Estado do Amazonas. Encontrou-se, que o Método Lúdico conseguiu atingir os objetivos curriculares de ensino com o uso dos cinco jogos elaborados especificamente para este trabalho contribuindo significativamente no processo de ensino-aprendizagem dos conceitos de geometria indicados pelos Parâmetros Curriculares Nacionais - PCN para o $5^{\circ}$ ano do Ensino Fundamental.

\section{INTRODUÇÃO}

Quando se tem oportunidade de acompanhar o processo de ensino-aprendizagem nos espaços formais de ensino observa-se ainda uma prática mecanizada e descontextualizada do próprio cotidiano escolar. E quando surgem questionamentos sobre o ato de ensinar, a frequente argumentação dentre as inúmeras que são elencadas é que as salas de aula estão lotadas e que os alunos têm dificuldade ou não querem aprender. Essas argumentações não deixam de ser importantes, porém, quando se discute essas inquietações encontra-se que "a reflexão critica sobre a prática se torna uma exigência da relação Teoria/Prática sem a qual a teoria pode ir virando blábláblá e a prática, ativismo" (FREIRE, 1996, p.24).

Refletir sobre o cotidiano escolar é justamente pensar em alternativas possíveis que venham diminuir o ativismo impregnado na rotina como maneira de controle dos alunos. É importante quando o educador caminha no processo de reflexão e entende que nem sempre os 


\section{REVISTA REAMEC}

Revista ta Rede Amazonitica de Eduraçäo

em Ciências e Matemática
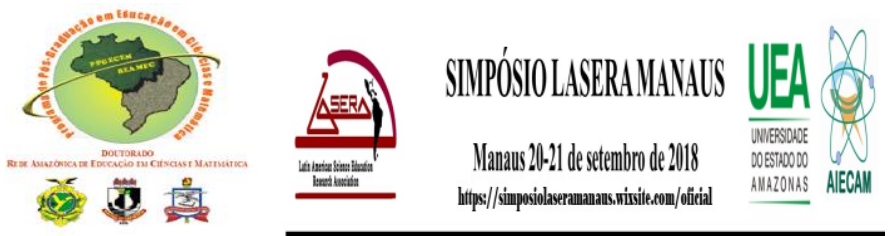

resultados são de responsabilidade do outro, mas que todos os envolvidos são atores nesse processo, até porque, o cotidiano escolar precisa ser discutido para que as mudanças significativas se efetivem e o processo de ensino e aprendizagem venha a ser menos conflitante entre os pares.

Campos (2007) diz que "o homem é a única criatura que precisa ser educada". É interessante pensar que de todos os seres vivos o ser humano é um dos seres dependente de outro ser para se constituir sujeito. E que até poder refletir e se fazer ouvir demanda todo um processo de dependência que o fará pensar e transformar ou só apenas reproduzir. Claro, que se compreende que o ser humano é bem complexo e que o sujeito construído pode não ser apenas reprodutor.

No entanto, para que aconteça uma apropriação pedagógica que corresponda à necessidade de ensino-aprendizagem nos espaços da sala de aula, a ruptura com o determinismo formal precisa acontecer. Ou seja, talvez em algumas situações o professor precise aprender novamente a ensinar se assim for preciso. O educador deve entender a prática pedagógica como um processo em constante construção e essa construção exige disposição, determinação e aceitação da necessidade de mudança e de renovação de sua prática (SOUZA NETO, 2005).

O ensino nos espaços educativos deve ser uma prática planejada pedagogicamente, com uma mediação fazendo relação entre a ciência do cotidiano e a ciência cientifica. Todavia, se o educador percebe que seu trabalho com o ensino não está alcançando o aluno, pois o ato de ensinar pode não ser o mesmo ato de aprender do aluno. $\mathrm{O}$ educador deve então analisar que ferramentas poderiam ser utilizadas além das que já utiliza e quais poderiam ser modificadas num processo de repensar a prática buscando a efetividade nesse processo (HAIDT, 2003).

Acredita-se que a busca de novas ferramentas depende em parte do conhecimento que o educador tem. Por exemplo, Oliveira (2006), em uma turma de segundo ano do segundo ciclo de uma escola Municipal na cidade de Manaus, desenvolveu uma metodologia lúdica estimulando a habilidade lógico-matemática. A turma onde os jogos foram usados tinham 36 alunos. Desses 36 alunos, somente 4 reconheciam as letras do alfabeto, diferenciando-as de desenhos e outros sinais gráficos. Enquanto que o restante dos alunos só sabia identificar o valor sonoro das partes iniciais ou finais de palavras (algumas letras ou sílabas), para 


\section{REVISTA REAMEC}

Revista ta Rede Amazonitica de Eduraçäo

em Ciências e Matemática

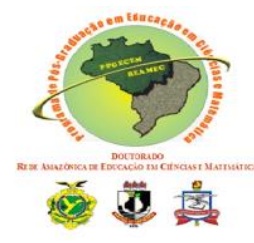

adivinhar e ler o restante da palavra. No entanto, ao usar recursos como jogo da memória e jogo de mosaico, a aprendizagem dos alunos foi estimulada, pois, dos 36 alunos, 30 aprenderam a ler e produzir pequenos textos.

É interessante refletir que conflitos como esse de Oliveira (2006) são constantes nos espaços educativos. Os professores têm que lidar com baixo rendimento na aprendizagem dos alunos e muitos desses alunos ainda se encontram acima da idade série estabelecidos na Lei de Diretrizes e Bases da Educação. E como se não bastassem os desníveis referentes à aprendizagem, ainda enfrentam a falta de recursos materiais para uma mediação efetiva (LUCKESI, 2005).

Mesmo com problemas como esses o educador precisa ver o aluno como aquele que aprende. Como um aprendiz no processo, não como mero observador, mas como sujeito que constrói e transforma o que aprendeu. Ao refletir sobre a educação dialética Freire diz que:

A educação pode fazer das pessoas donas da história ou acomodá-las ao mundo como um animal. A educação que apenas deposita conhecimentos no aluno (que Freire chamava de educação bancária) é monológica, ou seja, unidirecional, do professor para o aluno. Isto pode conduzir à opressão, porque nela os estudantes se tornam objetos e não sujeitos da aprendizagem (CAMPOS, 2007, p.11).

Pensa-se então que o processo dialético entre professor e aluno é justamente faze-los sujeitos da aprendizagem, como um processo de troca (CAMPOS, 2007). Segundo Freire (1996) falar com o aluno é diferente do falar para o aluno. Quando como educador percebe-se que o aluno está numa situação não muito privilegiada, pois precisa apreender o conhecimento e nessa apreensão se torna dependente, pode-se dizer que o processo de humanização da educação teve inicio. No entanto, a humanização da prática educativa ainda necessita da atitude de mudança, do educador e do aluno, para que o conhecimento seja contextualizado e tenha significado para àqueles que estão nesse processo, mesmo porque "ensinar e aprender são como duas faces de uma mesma moeda" (HAIDT, 2003). Portanto, o estudo da dinâmica do processo do ensino-aprendizagem é essencial para que se considere não a passividade, mas sim a atividade dos sujeitos que o constroem.

\section{O Lúdico no Ensino de Ciências}

A Ludicidade segundo os pressupostos já discutidos faz-se um suporte na prática educativa em diversas áreas do Ensino. Pesquisas realizadas no Ensino de Ciências 


\section{REVISTA REAMEC}

Revista da Rede Amazônica de Eduração

em Ciências e Matemática
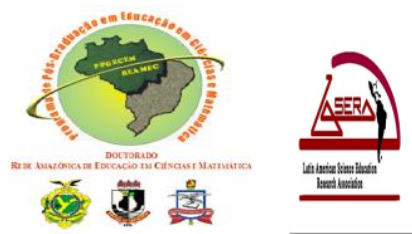

contrapõem a realidade educativa de que fazer ciência depende de muitos fatores e que esses fatores independem do fazer do professor. Como por exemplo, no ensino de conteúdos de biologia, sucatas e brinquedos foi um dos recursos usados (DAL-FARRA, 2004).

Este processo integra a mobilização de diferentes habilidades, e tem como ponto importante também, o fato dos próprios alunos poderem trazer materiais diversos que eles mesmos possuem. Além disso, o envolvimento com a construção de cadeias alimentares pode ser realizado em interessante processo de aprendizagem significativa. Nesta ótica, o que mais influencia o processo de aprendizagem é o que o aluno já sabe, sendo o papel principal do professor identificar isso e proporcionar procedimentos que se tornem claros e disponíveis para o aluno, como se fosse uma âncora para facilitar a aquisição de novas ideias e conceitos ( p.2).

Contextualizar um ensino não depende do nível cognitivo do aluno, mas sim da proposta do educador em transpor os saberes comuns para saberes científico. Bachelard (1996, p.09) diz que "diante do real, aquilo que cremos saber com clareza ofusca o que deveríamos saber" e ainda "a ciência, tanto por sua necessidade de coroamento como principio, opõe-se absolutamente à opinião". Saber mediar o ensino sem estar aprisionado pelo determinismo formal é uma forma de se opor a opinião da dependência no processo educativo, como por exemplo, usar o jogo como objeto de aprendizagem na interação dos conteúdos ajuda a desenvolver o senso critico sem precisar alardear que está fazendo isso (BERTOLETTI-DE-MARCHI E SILVA, 2004).

Colom (2004, p. 19) ao falar da (des)construção do conhecimento pedagógico diz que “o processo criador da ciência se inicia com o reconhecimento de problemas e culmina com a construção de teorias". Reconhecer que a apropriação do saber depende não só do desenvolvimento cognitivo, mas que a interação faz parte desse processo é relevante no ato de ensinar. Mesmo porque, o uso do jogo na interação dos conteúdos, independentemente da área cientifica pode servir como recurso avaliativo que ajuda a desmitificar a imagem do professor autoritário (OLIVEIRA \& MENEZES, 2010).

Carraher (2003, p.15) diz que "tanto os textos quanto os exercícios tradicionais sobrecarregam a memória do aluno". Ressalta-se, no entanto, que qualquer outro recurso, por mais lúdico que seja se for usado de maneira ativista pode também se tornar insatisfatório como recurso mediador. 


\section{METODOLOGIA}

Quanto à perspectiva metodológica, a investigação se baseou numa abordagem de métodos mistos em que houve uma triangulação concomitante, tanto na coleta como na análise dos dados. Esse itinerário foi legitimado através de técnicas de observação e entrevista e uso de prétest e póstest, bem como o desenvolvimento de um kit de jogos elaborados especificamente para este trabalho.

A pesquisa se realizou em uma Escola da rede Municipal de Ensino da Cidade de Manaus/Am, com 6 professores e 215 alunos do $5^{\circ}$ ano do Ensino Fundamental. O ensino pelo Método Lúdico dos conceitos de geometria no $5^{\circ}$ ano do Ensino Fundamental foi mais eficiente, visto que, os resultados foram estatisticamente significantes.

Os dados foram coletados de maneira simultânea e a análise considerou os pontos fortes das duas abordagens. Para a análise quantitativa foram usados programas estatísticos padrão Excel (no Windows) e Pacote Estatístico para as Ciências Socias (SPSS por suas siglas em Inglês) e para a parte qualitativa foram usados os delineamentos por categoria considerando o modelo teórico que fundamentou esse estudo.

\section{RESULTADOS E DISCUSSÃO}

\subsection{O aprendizado de conceitos de geometria no $5^{\circ}$ ano do ensino fundamental.}

Para se determinar se houve ou não diferenças no aprendizado dos conceitos de geometria de espaço e forma entre os três grupos pesquisados foi realizada uma Análise de Variância (ANOVA) seguida do post hoc de pares de Scheffe com os resultados do pós-test. Foi encontrada uma diferença estatisticamente significante no aprendizado entre os três grupos $\mathrm{F}(2,125)=32,69, \quad p=0,000 ;$ a qual mostrou que o $\mathrm{G} 2$ obteve uma nota significativamente superior $(x=8,06)$ aos grupos $\mathrm{G} 1(\mathrm{x}=5,62)$ e G3 $(\mathrm{x}=5,31)$.

Os grupos G1 e G3 não foram estatisticamente diferentes entre eles. Isto indica que o Método Lúdico (G2) foi melhor Método de ensino de Conceitos de Geometria do que o Método Tradicional (G1 e G3). Desta maneira, a hipótese nula foi rejeitada. Os ganhos no aprendizado dos alunos observados pelo pré-test e pós-test indicaram que o Método Lúdico foi o mais efetivo no ensino de conceitos de geometria. 


\section{REVISTA REAMEC}

Revista ta Rede Amazonitica de Eduraçäo

em Ciências e Matemática
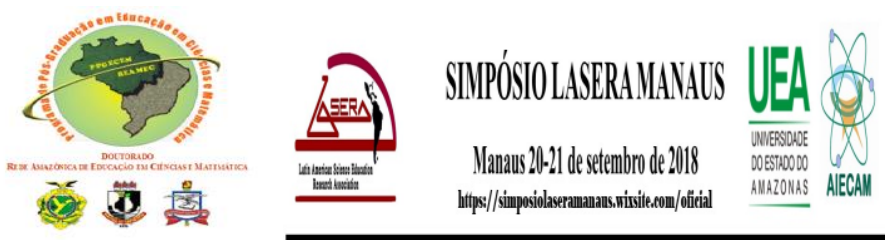

A análise dos dados também indicou que os grupos G1 e G3 obtiveram resultados significativamente diferentes no pré-test (5,33 e 4,22), o que mostra que esses dois grupos inicialmente tinham um nível de conhecimento sobre os conceitos de geometria diferente, sendo que o G1 demonstrou um nível superior aos demais. No pré-test o G2 $(4,73)$ não foi significativamente diferente dos G1 e G3, o que significa que era semelhante em conhecimentos a qualquer um dos grupos.

Ao se observar o perfil dos alunos no G1, que obtiveram a média mais alta no pré-test, encontrou-se que $21(87 \%)$ deles eram repetentes. Pode-se especular que a média do pré-test obtida do grupo G1 (x = 5,33) em comparação com os outros dois G2 (x=4,73) e G3 (x = 4,22) foi um reflexo da exposição aos conteúdos no passado pelos alunos desse grupo. Também poderia ser resultado desses alunos terem estudado o tema da geometria na semana anterior a aplicação do pré-test, constatado pelo fato de os alunos terem mostrado para a pesquisadora um exercício de estudo passado para eles pela sua professora. Porém, as notas foram em média abaixo do esperado e observando pelo lado negativo, estas crianças também não conseguiram notas significativas no pós-test, sugerindo que o método de ensino tradicional do qual participaram não ensinou os conceitos de geometria que seria esperado para eles conhecerem no final do $5^{\circ}$ ano segundo os PCN.

Resume-se que o Método Lúdico (G2) foi melhor para ensinar conceitos de geometria do que o Método Tradicional (G1 e G3). Embora grupos do Método Tradicional tenham ensinado os conceitos de geometria usando o livro didático, exercícios no caderno e uso do quadro branco, a assimilação desses conceitos pelos alunos não foi demonstrada no post-test em comparação com o G2 que usou os 05 jogos elaborados na presente pesquisa para o ensino dos conceitos de geometria.

Segundo alguns autores (por exemplo, CEDRO \& ROSA, 2010; RODRIGUES, KRÜGER E SOARES, 2010; SERRETINO E RIVERA, 2009; NOGUEIRA E BARBOSA, 2008), o Método Tradicional na prática educativa persiste em manter o pensamento de caráter classificador, catalisador e insuficiente para a assimilação da ciência e para uma relação criativa na prática educativa. Espera-se que tanto os alunos do Método Lúdico (G2), quanto os alunos do Método Tradicional (G1, G3) tenham o mesmo acesso ao conhecimento dos conceitos de geometria, pois os Parâmetros Curriculares Nacionais indicam quais os conteúdos de geometria que no $5^{\circ}$ ano servirão de base para que esses alunos possam se 


\section{REVISTA REAMEC}

Revista ta Rede Amazonitica de Eduraçäo

em Ciências e Matemática
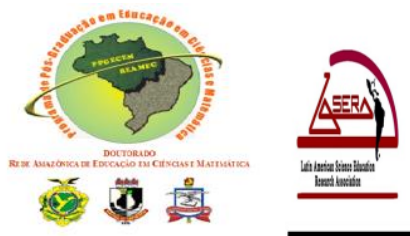

apropriar de conceitos mais complexos nas séries posteriores. Isto quer dizer que o esperado é que o aluno do $5^{\circ}$ ano encerre o ano letivo levando consigo o conhecimento planejado nos Parâmetros Curriculares Nacionais. No entanto, essa apropriação dos conteúdos de geometria relacionada ao espaço e forma mostrou-se não muito efetiva nos grupos G1 e G3. Pode-se supor que os professores destas turmas sejam cientes da obrigatoriedade desses conteúdos para a vida escolar dos seus alunos, no entanto, o método aplicado na sala de aula, Método Tradicional, mostrou pouca efetividade para o ensino desses conceitos.

Valente (2000) em sua pesquisa relata a experiência dos alunos num curso de pósgraduação e o mal-estar no uso do conhecimento matemático. O grupo de alunos dessa pesquisa, conforme relata Valente demonstrou apreensão e sentimento de derrota por não dominarem certos conteúdos básicos da matemática. Conteúdos que não foram assimilados por eles, não por dificuldade cognitiva, mas por conta do método empregado na prática de ensino desses conteúdos.

Ao se refletir sobre o reportado por Valente, pergunta-se se esses participantes da pesquisa do autor quando estudavam o $5^{\circ}$ ano teriam sido semelhantes aos participantes desta? Dito de outro modo será que estes, não conseguiram adquirir os conhecimentos de geometria, exigidos pelo currículo nacional, sentirão no futuro aquele mal estar em relação aos conhecimentos matemáticos? Isto é especialmente relevante porque a aversão pela matemática no ensino básico também já tem sido documentada (SERRETINO e RIVERA, 2009). Serretino e Rivera (2009) dizem que a matemática "se imparte en la Educación Básica sin referencia alguna a los conocimientos previos de los alumnos, de forma descontextualizada y mecánica, produciendo, en la mayoría de los casos, aversión y rechazo hacia la misma". A ruptura dessa aversão no ensino de matemática parece não depender da vontade do aluno segundo os estudos apontados, e sim da aplicação de recursos por parte do professor para fazer do ato de aprender uma extensão do ato de ensinar. Nogueira e Barbosa (2008) em seu estudo sobre a criança e o número no cotidiano e na escola dizem que na prática do ensino a contextualização do saber do aluno é significativa para a diminuição da aversão aos conteúdos de matemática.

A aprendizagem se insere num processo mais amplo que o espaço escolar, o que não minimiza o papel da escola na construção do conhecimento, mas revela a necessidade de compreendermos melhor o que as crianças nos "dizem" e sobre como ocorre o processo de aprendizagem, além de contribuir para que lancemos 


\section{REVISTA REAMEC}

Revista ta Rede Amazonitica de Eduraçäo

em Ciências e Matemática
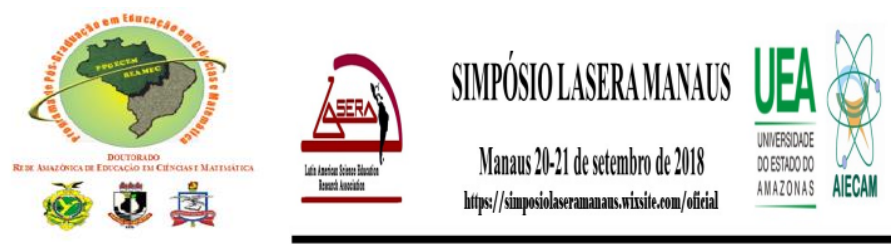

"novos olhares" para o que de fato devemos priorizar no processo de ensinar/aprender matemática (p.141)

Nesse olhar do que é significativo na ação do ensino vale a autoavaliação da prática. Saber ensinar é saber contextualizar conhecimentos, é saber aprender. E esse saber aprender depende do compromisso do educador de que os alunos que estão sobre os seus cuidados, cumprem etapas que ele não poderá acompanhar todo tempo. Por isso é necessário que o professor instigue o potencial do aluno deixando sua marca como educador.

Os achados referentes ao ensino dos conceitos de Geometria pelo Método Lúdico (G2) observados nesta pesquisa indicaram uma efetividade significativa. Esse resultado levou a pensar que a mudança de um cenário desanimador para um cenário mais animador na aprendizagem da matemática depende de práticas educativas desconstituídas da mesmice das aulas expositivas, repetitivas e monótonas. E que essas práticas podem constituir aulas que incidam em plausível condição de tornar menos árdua a tarefa de ensinar e o processo de aprender.

\section{CONCLUSÃO}

Como se vê, a prática educativa pode criar possibilidades de relações para o ensino da ciência. Todavia, acredita-se que o grande mérito na relação ensino-aprendizagem ainda fica por conta do educador, pois é ele que vislumbra o caminho da aprendizagem antes mesmo do aluno.

Portanto, as constatações que se faz não revelam novidades, no entanto, exigem uma mudança de postura frente aos processos de ensino e de aprendizagem, sendo necessário investigar sobre como o aluno aprende determinado conteúdo, analisar suas dificuldades e consultar quais são as suas necessidades sintonizando o conteúdo com a prática.

\section{REFERÊNCIAS}

BACHELARD, Gaston. A formação do Espirito Cientifico: contribuição para uma psicanálise do conhecimento. Rio de Janeiro: Contraponto, 1996.

BERTOLETTI-DE-MARCHI, Ana Carolina; SILVA, Flávia Biondoda.O Desenvolvimento de Objetos de Aprendizagem no Museu Zoobotânico Augusto Ruschi. Revista Novas 
Tecnologias na Educação. V.2, $\mathrm{n}^{\circ}$ 2, Novembro, 2004. Disponível em: www.capes.org.br, acesso em: 14.08.2010, as $14 \mathrm{~h}$.

BRASIL. Secretaria de Educação Fundamental. Parametros Curriculares Nacionais: Matemática. Brasilia: MEC/SEF, 1997.

CAMPOS, Judas Tadeu de. Paulo Freire e as Novas Tendências da Educação. Revista ECurriculum. São Paulo. V 3, n.1, dez. 2007. www.capes.org.br, acesso em: 14.08.2010, as 16 h.

COLOM. Antoni J. A (des)construção do conhecimento pedagógico: Novas perspectivas para a educação. Porto Alegre: Artmed, 2004.

DAL-FARRA, R. A; ACUNHA,Vitor Hugo Araújo .Cadeia e Teia Alimentar no Ensino de Ciências para Estudantes de $1^{\text {a }}$ a $4^{\text {a }}$ séries do Ensino Fundamental. Porto Alegre: UFRGS, 2004. Disponível em: www.ufrgs.edu.br, acesso em 20.03.2010, as 19 h.

FOUREZ, Gérard. A construção das ciências: Introdução a Filosofia e à Ética das Ciências. São Paulo: Unesp, 1995.

Crise no ensino de ciências? Revista Investigação em Ensino de ciências. V. 8, p.102-123, 2003. www.capes.org.br, acesso em: 08.02.2011, as 12 h.

FREIRE, Paulo. Pedagogia da autonomia.Saberes necessários à prática educativa. São Paulo: Paz e Terra, 1996.

HAIDT, R. C. C. Curso de didática geral. 7 ed. São Paulo: ática, 2003.

HAMBURGER, E. W. Apontamentos sobre o Ensino de Ciências nas séries escolares iniciais. Artigo. Revista Estudos Avançados. São Paulo. V.21, n.60, Maio-agosto, 2007.disponível em: www.capes.org.br. Acesso em: 18.08.2010, as 18 h.

KUHN. T.A. A estrutura das revoluções cientificas. 6 ed. São Paulo: Perspectiva, 2001.

LAKATOS, I. La metodologia de los programas de investigacion cientifica. Madrid: Alianza, 1982.

LUCKESI, Cipriano. Avaliação da Aprendizagem escolar. 17 ed. São Paulo: Cortez, 2005.

MAIA, Poliana Flávia; JUSTI, Rosária. Desenvolvimento de habilidades no ensino de ciências e o processo de avaliação: análise da coerência. Artigo. Ciênc. educ. (Bauru) vol.14 no.3 Bauru 2008. Disponível em: www.capes.org.br. Acesso em: 18.08.2010, as $18 \mathrm{~h}$.

MALAFAIA, G.; RODRIGUES, A.S.L. Uma reflexão sobre o ensino de ciencias no nivel fundamental da educação. Revista Ciencia\& Ensino. V.2, n.2. junho, 2008. Disponivel em: www.capes.org.br, acesso: 21.08.2010, as $20 \mathrm{~h}$.

Revista REAMEC, Cuiabá - MT, V. 6, n. Especial, dez 2018, ISSN: 2318-6674

Revista do Programa de Doutorado da Rede Amazônica de Educação em Ciências e Matemática

http://periodicoscientificos.ufmt.br/ojs/index.php/reamec 
MIRANDA,A.C.B; JÓFILI, Z.M.S.; LEÃO, A.M.A.C; LINS, M. Alfabetização Ecológica e Formação de Conceitos na Educação Infantil por meio de atividades lúdicas. Revista Investigação em Ensino de Ciências. V. 15, p.181-200, 2010. Disponivel em: www.capes.org.br, acesso em 21.08.2010.

MOREIRA, Marco Antonio. A teoria dos campos conceituais de Vergnaud, o ensino de ciências e a pesquisa nesta área. Revista Investigação em ensino de ciências. V.7, p.7-29, 2002. www.capes.org.br, acessoem: 03.02.2011, as $14 \mathrm{~h}$.

MORTIMER, Eduardo Fleury. Construtivismo, mudança conceitual e ensino de ciências: Para onde vamos? Artigo. Investigação em ensino de ciências. V.1, p. 20-39, 1996. Disponível em: www.capes.org.br acesso em: 20.03.2011.

NARDI, Roberto. Ensino de ciências e matemática I: temas sobre a formação de professores .São Paulo: Cultura Acadêmica, 2009.

OLIVEIRA, L. H. S. de. Estimulando a Inteligência Lógico-Matemática através de experiências Lúdicas nas $2^{\mathbf{a}}$ séries do $2^{\mathbf{o}}$ ciclo. Monografia. Manaus/AM: UEA, 2006.

OLIVEIRA, S.N.; LIMA, A.C; MENEZES, A.P.S. A utilização dos jogos de trilha como instrumento facilitador no ensino sobre o sistema genital humano, com alunos do $8^{\circ}$ ano. Revista Eletrônica Areté- Revista Amazônica de Ensino de Ciências. Manaus, v.3, n.5, 66-79, jan-jul.2010. Disponível em: www.uea.edu.br. Acesso em 17/08/2010 as 20 h.

RAMOS,P.; STRUCHINER,M. Concepções de Educação em pesquisas sobre materiais informatizados para o ensino de ciências e de saúde. Revista Ciência \& Educação. V. 15, n. 3, Bauru, 2009. Disponivel em: www.capes.org.br, acesso em: 21.08.2010. as 20h.

RODRIGUES, Carla Gonçalves; KRÜGER, Verno; SOARES, Alessandro Cury.Uma Hipótese Curricular para a Formação Continuada de Professores de Ciências e de Matemática.Ciência \& Educação, v. 16, n. 2, p. 415-426, 2010. Disponível em :www.capes.org.br, acesso em: 27.11.2010.

SOUZA NETO, Manoel Fernandes de. O ofício, A oficina e a Profissão: Reflexões sobre o lugar social do professor. CAD. Cedes. Campinas, v. 25, n.66 maio/ago.2005.

SCARINI, Anne L; PACCA, Jesuína L. A. O Professor de Física em sala de aula: Um instrumento para caracterizar sua atuação. Artigo. Investigação em Ensino de Ciências, V. 14, p. 457-477, 2009.

VILLANI, A.; PACCA, J.L.A. Construtivismo, Conhecimento Científico e Habilidade Didática no Ensino de Ciências. Artigo. Revista da Faculdade de Educação. V.23, n. 1-2. São Paulo. Jan-dez, 1997. Disponível em: www.capes.org.br. Acesso em 18.08.10, as $20 \mathrm{~h}$. 


\section{REVISTA REAMEC}

Revista ta Rede Amazonitica de Eduraçäo

em Ciências e Matemática

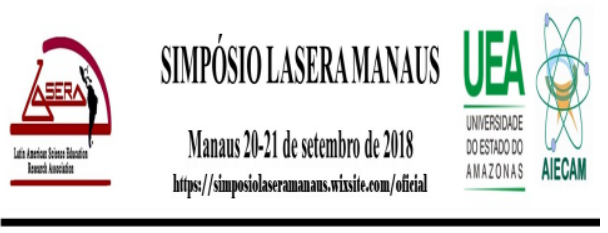

